\title{
IDENTIFICATION AND QUANTIFICATION OF SOME CAPSAICINOIDS IN PADRÓN PEPPER (CAPSICUM ANNUUM L. VAR. ANNUUM) FRUITS
}

\author{
B. Estrada, M. A. BERnAl, F. POMAR and F. MERINO* \\ Departamento de Bioloxía Animal, Bioloxía Vexetal e Ecoloxía, Facultade de Ciencias, \\ Universidade da Coruña. A Zapateira s/n 15071 A Coruña. Spain
}

(Received: 15 November 2000; accepted: 15 June 2001)

Capsaicinoid and phenolic contents were determined at different maturation stages of the pepper fruit, with an increase being observed in the levels of both components. The increase in total soluble phenolics probably reflects the accumulation of capsaicinoids seen throughout development. Four different capsaicinoids and their precursor vanillylamine were identified in the cultivars studied. Capsaicin, dihydrocapsaicin and nordihydrocapsaicin showed the same accumulation patterns in all stages, but homodihydrocapsaicin appeared only in the last stage.

Keywords: pepper, Capsicum annum L, capsaicinoids, phenolics, HPLC determination

Phenolic compounds constitute one of the most important groups of natural products, which possess an aromatic ring bearing one or more hydroxyl groups (HARBONE, 1980). Some phenolics, such as hydroxycinnamic acids and flavonoids, are found in all the plant groups, but in very different quantities. However, other phenolics are exclusive to a particular genus and species (SWAIN, 1979; MACHEIX et al., 1990).

These compounds are present in all plant tissues and are often the most abundant secondary metabolites in fruits, where they sometimes reach high concentrations. Phenolics are also important because of their contribution to the sensory quality of fruits- color, astringency, bitterness, and flavor (MACHEIX et al., 1990). The levels of phenolic compounds during growth and maturation vary strongly depending on the availability of the precursors of phenolic molecules and the activity of the enzymes involved in the biosynthesis of these precursors in interconversions between phenolic molecules or in their degradation (LUCKNER, 1980).

There is a group of phenolic compounds characteristic of some fruits of the genus Capsicum, capsaicin and other related compounds commonly called capsaicinoids

* To whom correspondence should be addressed.

Tel.: +34-981-167000; Fax.: +34-981-167065; E-mail: fuenme@udc.es 
(BENNET \& KIRBY, 1968). The main capsaicinoids in hot peppers are capsaicin, dihydrocapsaicin and nordihydrocapsaicin. A great number of naturally occurring capsaicinoids have been identified as minor components (JURENTISCH et al., 1979).

The capsaicinoids are synthesized by the condensation of vanillylamine with a short-chain branched fatty acid. The short-chain branched fatty acid moiety is biosynthetically derived from valine, while the vanillylamine moiety comes from Lphenylalanine, via the phenylpropanoid pathway (LEETE \& LOUDEN, 1968). This pathway begins with the deamination of phenylalanine to produce cinnamic acid, which flows through this pathway to yield $p$-coumaric, caffeic and ferulic acids. The first part leads to the formation of a wide range of secondary metabolites such as coumarins, flavonoids and lignin. The latter part from ferulic acid to capsaicin is only found in the fruits of the genus Capsicum.

Many studies have reported the accumulation of capsaicinoids in Capsicum fruits in relation to fruit age, size and stage of development (IWAI et al., 1979; SALGADOGARCIGLIA \& OCHOA-AlEJO, 1990; SuKRASNO \& YEOMAN, 1993). The results are similar given the fact that capsaicinoids begin to accumulate in the early stages of fruit development and this accumulation achieves its maximum rate as the fruit approaches the end of its growth phase (HALL et al., 1987). However, the concentration of capsaicinoids varies depending on the different pepper cultivars examined (GOVINDARAJAN et al., 1987).

The Padrón pepper (Capsicum annuum L. var. annuиm) is a commercial cultivar available in the region of NW Spain, Galicia, and widely accepted for fresh market consumption. The fruits are commercialized when immature and their flavor is not very hot, because they contain only low levels of capsaicin, the main compound causing pungency in peppers. This low capsaicinoid content is the most important fruit quality attribute. Phenolic compounds may contribute greatly to the organoleptic characteristics of the fruit. The purpose of this study is to examine the changes in the levels of soluble phenolics and capsaicinoids in the pepper fruit, cv. Padrón, during growth and ripening.

\section{Materials and methods}

\subsection{Plant material}

Plants of Capsicum annuum L cv. Padrón were grown in a greenhouse on the campus of the University of La Coruña from April to September. Anthesis began ca 3 months after germination; individual flowers were numbered and the date of flowering recorded. Pepper fruits were harvested every 7 days from 14 (stage 1) to 42 (stage 5) days after flowering and individual weights of the whole peppers were measured. The fruits were subsequently stored at $-30^{\circ} \mathrm{C}$ until processed. 


\subsection{Extraction and quantification of capsaicinoids by HPLC}

Capsaicinoids were extracted from Padrón pepper fruits using the technique described by COLLINS and co-workers (1995) with modifications (ESTRADA et al., 1998).

Pepper fruits were oven-dried at $60{ }^{\circ} \mathrm{C}$ for $2-5$ days, their dry weight (DW) determined, ground using a laboratory mill and stored in sealed plastic tubes at room temperature prior to extraction. The capsaicinoids were extracted from $1.0 \mathrm{~g}$ of the ground pepper in $10 \mathrm{ml}$ of acetonitrile by heating to $80^{\circ} \mathrm{C}$ for $4 \mathrm{~h}$. The suspended material was allowed to settle and the supernatant was extracted and centrifuged at $100 \mathrm{~g}$ for $10 \mathrm{~min}$ and then filtered $(0.45 \mu \mathrm{m}$ Whatman on a $10 \mathrm{ml}$ disposable syringe) into a $2 \mathrm{ml}$ glass sample vial, capped and stored at $5{ }^{\circ} \mathrm{C}$ until analyzed. A $10 \mu \mathrm{l}$ aliquot was injected into the HPLC column.

The samples were analyzed using a Waters LC616 System equipped with a Waters 717plus Autosampler, a Waters Temperature Control Module, a Waters 996 Photodiode Array Detector and Millennium Software for data processing. Reverse phase HPLC was carried out on a Spherisorb $\mathrm{C}_{18}$ column $(5 \mu \mathrm{m}$ particle size, $150 \mathrm{~mm} \times$ $46 \mathrm{~mm}$ ). A precolumn guard cartridge, Spherisorb $\mathrm{C}_{18}$ column, was also used. To determine the capsaicinoids, the HPLC operating conditions were: $25^{\circ} \mathrm{C}$, a flow rate of $1 \mathrm{ml} \mathrm{min}^{-1}$, and a $14 \mathrm{~min}$ run. The mobile phase was isocratic with $50 \%$ solvent $\mathrm{A}$ (100\% acetonitrile-HPLC grade) and 50\% B [10\% acetonitrile (by volume) in water].

The vanillylamine and the capsaicinoids were identified on the basis of their retention times and analysis of the spectra of the different peaks. The mean retention time under these conditions was: vanillylamine $4.40( \pm 0.04) \mathrm{min}$, nordihydrocapsaicin, $7.00( \pm 0.06) \mathrm{min}$, capsaicin $7.42( \pm 0.05) \mathrm{min}$, dihydrocapsaicin $10.50( \pm 0.05) \mathrm{min}$ and homodihydrocapsaicin $11.50( \pm 0.04) \mathrm{min}$.

\subsection{Extraction and determination of soluble phenolics}

Soluble phenolics from Padrón pepper fruits were extracted by the same procedure as capsaicinoids. Total soluble phenols were determined using the FolinCiocalteu reagent according to the method of SINGLETON and ROSSI (1965). The content of the soluble phenols was calculated from a standard curve obtained using different concentrations of ferulic acid. 


\section{Results}

\subsection{Soluble phenolic and capsaicinoid content}

Figure 1 shows the changes in soluble phenolics and capsaicinoids that the pepper fruit underwent during the maturation process. Soluble phenolics were already detected at the first stage, 14 days after flowering. Their levels were similar during the second, third and fourth stages $-21,28$ and 35 days after flowering, respectively. The Padrón pepper showed a moderate increase in these levels at the end of development, with the highest values found in the 5th stage, 42 days after flowering.

The pattern of capsaicinoid accumulation was similar to that of soluble phenolics. Their levels remained low for 21 days, but 28 days after flowering capsaicinoids increased moderately, and finally, the cv. Padrón pepper reached their highest levels in the last stage, 42 days after flowering (Fig. 1). However, the increase in capsaicinoids was higher than in soluble phenolics.

\subsection{Identification of some capsaicinoids}

Table 1 shows the different capsaicinoids detected in the Padrón pepper fruit. Capsaicin, dihydrocapsaicin and nordihydrocapsaicin, showed the same pattern of accumulation, with the latter being of low concentration. The other homologue of capsaicin, homodihydrocapsaicin, was detected only 42 days after flowering and in significantly lower levels when compared to the other compounds. Vanillylamine, the precursor of capsaicin before condensation with 8-methyl-6-nonenoic acid, could be detected 14 days after flowering, and its content moderately increased until the 35th day. Furthermore, the pepper fruit showed a great increase in this compound at the end of development, with the highest values found 42 days after flowering (Table 1).

Table 1

Vanillylamine and capsaicinoids in whole pepper during growth ${ }^{a}$

\begin{tabular}{cccccc}
\hline D.a.f. & CAP & DHC & NDHC & HDHC & VAN \\
\hline 14 & $64.3 \pm 8.0$ & $47.2 \pm 4.0$ & $21.5 \pm 0.8$ & nd & $26.0 \pm 0.7$ \\
21 & $57.0 \pm 5.0$ & $38.2 \pm 5.0$ & $19.7 \pm 0.7$ & nd & $44.0 \pm 0.8$ \\
28 & $161.5 \pm 10.0$ & $105.0 \pm 8.0$ & $40.2 \pm 0.6$ & nd & $48.0 \pm 0.9$ \\
35 & $96.0 \pm 6.0$ & $56.4 \pm 5.0$ & $22.0 \pm 0.9$ & nd & $55.4 \pm 1.0$ \\
42 & $426.0 \pm 20.0$ & $275.0 \pm 10.0$ & $95.5 \pm 1.0$ & $39.0 \pm 0.7$ & $93.0 \pm 0.9$ \\
\hline
\end{tabular}

a Data are expressed in $\mathrm{ng} \mathrm{g}^{-1} \mathrm{DW} \pm$ SD. D.a.f.: Days after flowering; CAP: capsaicin; DHC: dihydrocapsaicin; NDHC: nordihydrocapsaicin; HDHC: homodihydrocapsaicin; VAN: vanillynamine; nd: not detected 


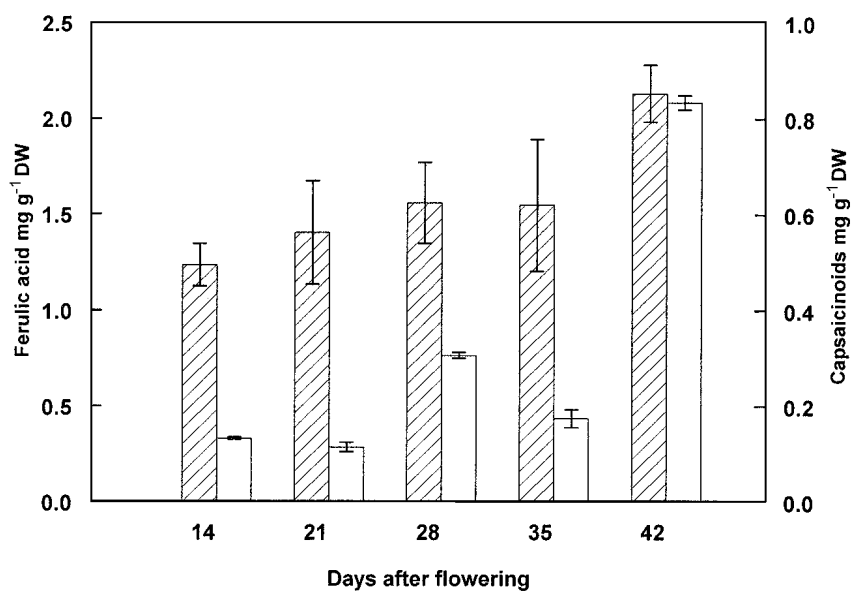

Fig. 1. Changes in soluble phenolics and capsaicinoids in pepper fruits at different stages of development, expressed in mg eq. ferulic acid/g DW. Values are mean of 30 fruits in three different extractions. Bars show SD : soluble phenolics, $\square$ : total capsaicinoids

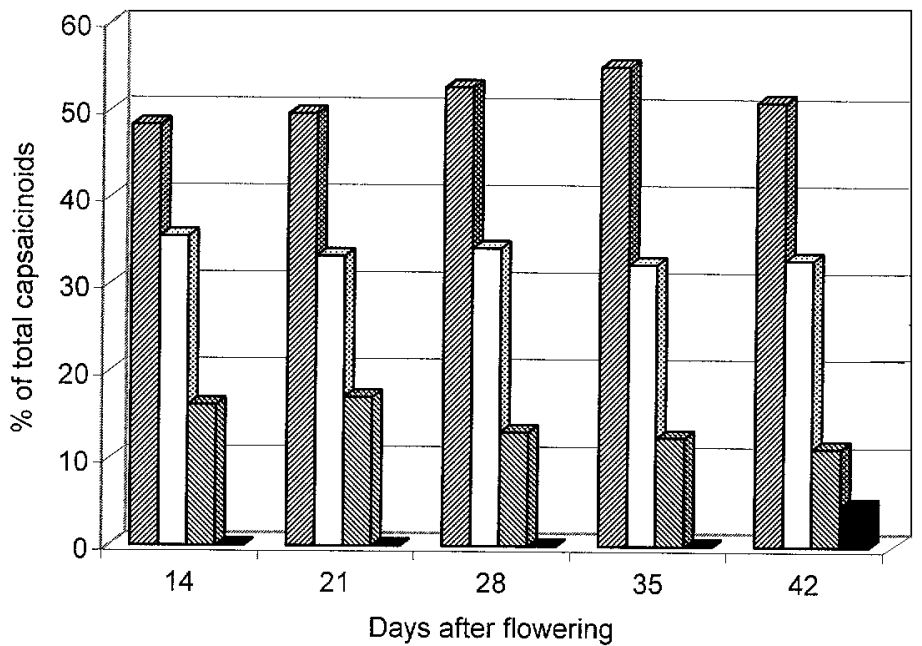

Fig. 2. Percentage of the individual capsaicinoids over the total capsaicinoid content. $\square$ : capsaicin, $\square$ : dihydrocapsaicin, $\$$ : nordihydrocapsaicin and $\square$ : homodihydrocapsaicin 
There were no significant changes in the proportion of the capsaicinoids during the course of development. Capsaicin was always the major component, followed by dihydrocapsaicin and nordihydrocapsaicin in all the stages studied (Fig. 2). However, it is noteworthy that the percentage of nordihydrocapsaicin decreased over the course of development, with the lowest value found 42 days after flowering.

\section{Conclusions}

Changes of the phenolic pool are observed during the maturation of different species of fruits. Since the first research carried out on Prunus domestica (SWAIN \& HILLIS, 1959) there have been numerous investigations confirming that soluble phenolics have the highest levels during the initial stages of development, and that these levels fall during growth (MACHEIX et al., 1990; MAYR et al., 1995). In some cases, however, as in red fruits, the levels of phenolics rise again, due to the accumulation of flavonoids such as in grape berries (PIRIE \& MULLINS, 1980), or anthocyanins. The latter is the case of the tomato fruit, in which the increase in total phenol content is caused mainly by a strong increment in naringerin and other unidentified compounds in the skin (WARDALE, 1973). This situation is similar to that of pepper, cv. Padrón, whose increase in the content of soluble phenols during maturation probably reflects the formation of the major compounds, the capsaicinoids, since they are also detected by the Folin Ciocalteau reagent (BAJAJ, 1980). The increase in capsaicinoids and the more direct precursor, vanillylamine, mask the drop in the other free phenolics such as protocatechuic acid, chlorogenic acid and cinnamic acid observed in Padrón pepper (ESTRADA et al., 2000).

The relative concentrations of the three principal homologues, capsaicin, dihydrocapsaicin and nordihydrocapsaicin, found in all species have been considered characteristic of the species and subspecies. JURENITSCH and co-workers (1979) proposed a chemotaxonomic classification based on the capsaicinoid composition which agreed, to some extent, with the traditional classification based on flower morphology and seed characteristics. The key to the identification of the individual Capsicum species is based on the sum of the three principal individual capsaicinoids and their levels. The proportions found in the cv. Padrón are the ones that correspond to Capsicum annuum var. annuum in this key. As regards homodihydrocapsaicin, it could be detected during the last flowering stage. This minor capsaicinoid has been found only in a few cultivars of different species of Capsicum (IWAI et al., 1979; CoLLINS et al., 1995).

When the total amount of capsaicinoids in cv. Padrón were analyzed, it was observed that in the last stage, this value was about $0.83 \mathrm{mg}$ per $\mathrm{g}$ of dry weight $(0.083 \%)$. If these results are compared with other hot varieties of Capsicum annuиm 
(Table 2) (COLlins et al., 1995; CONTRERAS-PADILla \& YAHIA, 1998), it can be seen that the content of capsaicinoids in the Padrón cultivar is very low even in the last stage. The pepper fruits vary considerably in their pungency according to capsaicinoid content per $\mathrm{g}$ of dry weight, covering a range of values evaluated as a mild variety, 0.1 to $0.2 \%$; medium, 0.2 to $0.4 \%$, hot 0.4 to $0.6 \%$ and very pungent variety, over $0.6 \%$ (GOVINDARAJAN et al., 1987). In conclusion, if we take the capsaicinoid content of the Padrón pepper into account, this cultivar may be considered to be mild, and therefore suitable for fresh consumption, especially during the early stages.

Table 2

Maximum concentration of capsaicinoids in different cultivars of Capsicum annuum $L$

\begin{tabular}{lc}
\hline Cultivar & $\begin{array}{c}\text { Capsaicinoids } \\
\text { mg/g DW }\end{array}$ \\
\hline Padrón $^{\text {Pasilla }}$ & 0.83 \\
Cascabel $^{\mathrm{a}}$ & 3.70 \\
Cubanella $^{\mathrm{a}}$ & 1.37 \\
Jalapeño $^{\mathrm{a}}$ & 12.17 \\
Nuevo Mexico $^{\mathrm{a}}$ & 20.37 \\
De árbol & 0.81 \\
Piquin $^{\mathrm{b}}$ & 80.52 \\
\hline
\end{tabular}

${ }^{\mathrm{a}}$ COLLINS et al., $1995 ;{ }^{\mathrm{b}}$ CONTRERAS \& YAHIA, 1998

This work was supported by Xunta de Galicia (XUGA 10301/A/95). The authors are grateful to Mrs. M. LEMA (S.X.A.I.N., Univ. of A Coruña) for her technical assistance.

\section{References}

BAJAJ, K. L. (1980): Colorimetric determination of capsaicin in Capsicum fruits. J. Assoc. Off. Anal. Chem., $63,1314-1316$.

Bennett, D. J. \& Kirby, G. W. (1968): Constitution and biosynthesis of capsaicin. J. Chem. Soc. C, 442-446.

Collins, M. D., Mayer Wasmund, L. \& Bosland, P. W. (1995): Improved method for quantifying capsaicinoids in Capsicum using high-performance liquid chromatography. HortScience, 30, 137-139. 
CONTRERAS-PADILLA, M. \& YAHIA, E. M. (1998): Changes in capsaicinoids during development, maturation and senescence of chili peppers and relation with peroxidase activity. J. agric. Fd Chem., 46, 2075-2079.

Estrada, B., Pomar, F., Díaz, J., Merino, F. \& Bernal, A. (1998): Effects of mineral fertilizer supplementation on fruit development and pungency in "Padrón" peppers. J. hortic. Sci. Biotech., 73, $493-497$.

Estrada, B., Pomar, F., Díaz, J., Bernal, A. \& Merino, F. (2000): Fruit development in Capsicum annиит L.: changes in capsaicin, lignin, free phenolics, and peroxidase patterns. J. agric. Fd Chem., 48, 6234-6239.

GovindaRAJAN, V. S., RAJAlaKshmi, D. \& Chand, N. (1987): Capsicum-production, technology, chemistry and quality. Part IV. Evaluation of quality. Crit. Rev. Fd Sci. Nut., 25, 185-282.

Hall, R. D., Holden, M. A. \& Yeoman, M. M. (1987): The accumulation of phenylpropanoid and capsaicinoid compounds in cell cultures and whole fruit of the chili pepper, Capsicum frutescens. Plant. Cell. Tis. Organ. Cult., 8, 163-176.

HARBone, J. R. (1980): Plant phenolics. -in: Bell, E. A. \& ChaRlwood, B. V. (Eds) Encyclopedia of plant physiology (New Series), Vol. 8, Springer Verlag, Berlin, pp. 329-402.

IWAI, K., SUZUKI, T. \& FUJIWAKE, H. (1979): Formation and accumulation of pungent principle of hot pepper fruits, capsaicin and its analogues, in Capsicum аппиит var. аппиит cv. Karayatsubusa at different growth stages after flowering. Agric. biol. Chem., 43, 2493-2498.

JuRentisch, J., KubELKA, W. \& JeNTZSCH, K (1979): Identification of cultivated taxa of capsicum: taxonomy, anatomy and composition of pungent principles. Planta Med., 35, 174-179.

LeEte, E. \& Louden, M. C. L. (1968): Biosynthesis of capsaicin and dihydrocapsaicin in Capsicum frutescens. J. Amer. Chem. Soc., 90, 6837-6841.

LUCKNER, M. (1980): Expression and control of secondary metabolism. -in: BELL, E. A. \& CHARLwOOD, B. V. (Eds) Encyclopedia of plant physiology (New Series), Vol. 8, Springer Verlag, Berlin, pp 23-61.

MacheiX, J. J., Fleuriet, A. \& Billot, J. (1990): Fruit phenolics. CRC Press, Boca Ratón, Florida, pp. $1-4,152,239$.

Mayr, U., Treutter, D., SAntos-Buelga, C., Bauer, H. \& Feuch, W. (1995): Developmental changes in the phenol concentrations of "Golden delicious" apple fruit and leaves. Phytochemistry, 38, $1151-1155$.

PIRIE, A. J. G. \& Mullins, M. G. (1980) Concentracion of phenolics in the skin of grape berries during fruit development and ripening. Am. J. Enol. Vitic., 31, 34-37.

SAlgado-GaRCiglia, R. \& OCHOA-AlEJo, N. (1990): Increased capsaicin content in PFP-resistant cells of chili pepper (Capsicum annuum L.). Plant Cell Rep., 8, 617-620.

Singleton, V. L. \& Rossi, J. A. (1965): Colorimetry of total phenolics with phosphomolybdic phosphotungstic acid reagents. Am. J. Enol. Vitic., 16, 144-158.

Sukrasno, N. \& YeOman, M. M. (1993): Phenylpropanoid metabolism during growth and development of Capsicum frutescens fruits. Phytochemistry, 32, 839-844.

Swain, T. (1979): Phenolics in the environment. -in: Swain, T., Harbone, J. \& VAN Sumere, C. F. (Eds) Biochemistry of plant phenolics, recent advances in phytochemistry. Plenum Press, New York, pp. 617-640.

SwaIN, T. \& HILLIS, W. E. (1959): The phenolic constituents of Prunus domestica. The quantitative analysis of phenolic constituents. J. Sci. Fd Agric., 10, 63-81.

WARDALE, D. A. (1973): Effect of phenolic compounds in Lycopersicon esculentum on the synthesis of ethylene. Phytochemistry, 12, 1523-1527. 